\title{
Chloride retention and release in a boreal forest soil - effects of soil water residence time and nitrogen and chloride loads
}

David Bastviken, ${ }^{1, *}$ Per Sandén, ${ }^{2}$ Teresia Svensson, ${ }^{2}$ Carina Ståhlberg, ${ }^{3}$ Malin Magounakis, ${ }^{2}$ and Gunilla Öberg ${ }^{2}$

${ }^{1}$ Department of Geology and Geochemistry, Stockholm University, 10691 Stockholm, Sweden

${ }^{2}$ Swedish Institute of Climate Science and Policy Research, Linköping University, 601 74 Norrköping, Sweden

${ }^{3}$ Department of Water and Environmental Studies, Linköping University, 58183 Linköping, Sweden

* Corresponding author: David Bastviken, E-mail: david.bastviken@geo.su.se

Phone: +468 167324, Fax: +4686477855 


\section{Supporting information}

\section{Contents:}

Table S1

Table S2

Table S1. Experimental setup of treatments according to a factorial design. There were a total of three factors (water, nitrogen, and chloride load), eight treatments, and three replicate lysimeters per treatment. See text for details.

\begin{tabular}{|c|c|c|c|c|c|c|c|}
\hline \multicolumn{2}{|c|}{ Low Water } & \multicolumn{3}{c|}{ High Water } \\
\hline \multicolumn{2}{|c|}{ Low Cl } & \multicolumn{2}{c|}{ High Cl } & \multicolumn{2}{c|}{ Low Cl } & \multicolumn{2}{c|}{ High Cl } \\
\hline Low N & High N & Low N & High N & Low N & High N & Low N & High N \\
\hline Treatment & Treatment & Treatment & Treatment & Treatment & Treatment & Treatment & Treatment \\
& 2 & 3 & 4 & 5 & 6 & 7 & 8 \\
\hline
\end{tabular}


Table S2. Mass balance of chloride in the soil lysimeters for the whole experiment (day 0-127). Load refers to the different treatments (see text for details), and addition corresponds to the total addition throughout the incubation period. Recovery refers to the mean percentage recovered relative to the addition.

\begin{tabular}{|c|c|c|c|c|c|}
\hline \multirow[t]{2}{*}{ Load } & \multirow[t]{2}{*}{ Addition } & \multicolumn{3}{|c|}{ In leachate } & \multirow{2}{*}{$\begin{array}{l}\text { Recovery (\%) } \\
\text { Mean (Min-Max) }\end{array}$} \\
\hline & & Mean & Median & Min-Max & \\
\hline \multicolumn{6}{|l|}{ Chloride (mg) } \\
\hline Low (low water) & 4.0 & 2.47 & 2.40 & $2.11-7.58$ & $61(52-76)^{*}$ \\
\hline Low (high water) & 4.0 & 2.87 & 2.85 & $1.68-3.95$ & $71(42-98)$ \\
\hline High (low water) & 12.1 & 8.15 & 8.62 & $5.72-9.15$ & $67(47-76)$ \\
\hline High (high water) & 12.1 & 7.00 & 6.98 & $5.92-8.30$ & $58(59-62)$ \\
\hline
\end{tabular}

